\title{
Art-Samples. \\ On the Connection between Art and Science
}

\begin{abstract}
I want to illustrate the closeness of art and science by drawing on the example of the scientific practice of sampling. I want to show that Goodman's idea of seeing works of art as samples may lead to a deeper understanding of art, and maybe also of science. By way of doing so I will first explain the function of samples in science and in a second step show how typical features of samples in science may be applied to pictures, here especially those of abstract art.
\end{abstract}

Painting is a science and should be pursued as an inquiry ... of which pictures are but the experiments (Constable).

Here I want to follow up on the idea of understanding works of art, especially pictures, analogously to samples in science (e.g. spot checks and also experiments). To my knowledge, this idea was first explicitly stated by Nelson Goodman. Of course, I do not wish to deny that the comparison and, by extension, an approximation of artistic and scientific endeavours is as old as art, respectively science itself (cf. Gombrich 1977, I.1). Furthermore, if one wishes to do so, one can see the whole enterprise of "philosophical disenfranchisement" (cf. Danto 1986, chap. I) as an attempt to deny the equality of art and science respectively philosophy. Also one should take note of the fact that, for most artists too, art is not to be understood as science.

Despite these internal attempts at distinction as well as external attempts at disenfranchisement, I want to followingly illustrate the closeness of art and science by drawing on the example of the scientific practice of sampling. I want to show that Goodman's idea of seeing works of art as samples may lead to a deeper understanding of art, and maybe also of science. By way of doing so I will first explain the function of samples in 
science and in a second step show how typical features of samples in science may be applied to pictures, here especially those of abstract art.

\section{Samples in Science}

Certainly no one doubts that samples play an important role in science. Consider, for example, samples in medicine, biology, chemistry, criminology, meteorology etc. Samples in these sciences are typically characterized by the act of taking a part of a larger whole and analyzing it. We have a different kind of sample, for instance, if a scientist examines something new and artificially developed in an experiment. In this case the sample is not part of the whole in the way a water sample is part of a lake, but is, at best, part of a future whole. This is the case, for instance, if a pharmacist attempts to develop a new drug. A further distinction in the practice of sampling is whether the whole, from which the sample is taken, is exhaustible or inexhaustible. A water sample taken from a bottle of mineral water is, for example, exhaustible, while a sample from the sea is practically inexhaustible.

Despite the differences among kinds of samples, one common feature is easily identified. Samples depend on a frame, i.e. a theory or a system, within which the relevant features of a sample are defined. To clarify these so far cursory remarks two examples can be adduced: Let's say I decide to lay in a stock of potatoes for the winter and, for this reason, go to a farmer in order to get a sample. The potatoes are tasty and have all features of good potatoes. I buy two hundredweights, but unfortunately, in the course of the winter, find out that many are worm-eaten and bitter. The sample taken was bad. It was bad because the essential features of the taken sample did not correspond to those of the potatoes eaten in the winter. We should note the following: The sample is bad, but not wrong. It is bad because it has not got the essential features that would be representative of the respective potato harvest. ${ }^{1}$

A sample can, of course, also be simply false, for instance, if a red fabric pattern is to exemplify green fabric. It is, in this case, just as false as if "red" were applied to a green object (cf. $W W, 133$ ). Therefore a distinction has to be made whether something is not a sample of a feature or just not a "fair" one (ibid., 134). 
An interesting question in this context is which conclusions can be drawn from this failure for the practice of taking samples in the future. It is obvious that, for practical reasons, I can impossibly sample all potatoes that I intend to eat in the coming winter. On the other hand, what I can do is take a number of samples in order to increase the likelihood that the sample is representative. I can furthermore try to improve my practice of sampling by paying attention to different features. I can, for example, develop a "theory" of the way the colour, the consistency etc. of potatoes give indications as to their shelf life and taste. The consequence for future samples of modifying my "theory" like this is that features will be examined that were so far considered irrelevant. That is, I examine whether the sample has or has not got certain features that I have so far not examined. Modifications of this sort are likely to be found in the sampling practices of all sciences and are often the basis of scientific progress. While, in the case of my potato example, the practice of sampling is exhausted when all potatoes bought are used up and I thus know whether the sample was representative or not, in the case of most scientific samples, the samples are inexhaustible. Consider the following example. On behalf of the waterworks a hydrologist takes a sample from Lake Constance. She wants to find out whether the water in Lake Constance is potable. The quality of the water sample indicates that the water in Lake Constance is potable. A number of swimmers, who have accidentally drunk water from Lake Constance, lose their trust in science, when they fall ill shortly afterwards. Was the sample bad?

Whereas in the first example (the potato sample) the question can clearly be answered in the positive, the case is slightly more complicated in the second. The water sample had properties other than those of the water, in which the swimmers have swum. The fundamental difference between the two samples described above is that, in the first case, there is ultimately a fact of the matter whether the sample is good or bad when the hypothesis is exhausted, i.e. when all potatoes are eaten and they correspond to the sample in all their essential features. This is in fact impossible in the second case. It will never be possible to finally decide whether a sample is good, since it will always be possible that further samples will be inconsistent with the samples on which induction has been based so far. 
But how can the quality of the samples taken so far be assessed in view of a new sample?

By way of example, let us imagine that the hydrologists of the waterworks in Constance have so far taken 1000 samples according to a certain practice of taking samples. This practice is based on certain theoretical background assumptions, for instance, probability theory, fundamentals of water properties etc. and a more or less explicit way of handling the practice of sampling, for instance, demanding a standard of cleanliness for the containers used for sampling or defining areas of the lake, from which samples can and cannot be taken. Against this background a hydrologist takes a further sample, which is not potable. It is obvious that one or two samples hardly justify the assumption that Lake Constance no longer has the quality of drinking water nor that the practice of sampling should be called into question for this reason. The hydrologist has to take further samples and only if they are not potable with a certain frequency will she come to the conclusion that the water in Lake Constance is no longer potable. We can assume this to typically be the case if we think of the role of samples in science. The closest case, on the other hand, probably is one, in which the samples still have the quality of drinking water, but in which people who drink water from Lake Constance exhibit certain disease patterns with increased frequency. This will lead to the assumption of a causal link between drinking water from Lake Constance and these disease patterns. This can lead to changing the features, on the basis of which the quality of drinking water will be assessed. So effects of this kind do not only affect the practice of sampling but also the background theory. If we take a look at the historical development of the identification of which features water must possess in order to be potable, we find that in the beginning there were relatively few criteria, for instance, smell and clarity, and only gradually over time further requirements were made on the quality of drinking water and others were dropped. The considerations so far as regards the water sample may be summed up as follows.

In the example there are four possibilities: (a) the sample taken by the waterworks was merely accidentally bad. (b) The practice of sampling is revised. It is no longer sufficient to take one sample from 20 meters below the surface and a kilometre from the shore. Instead samples have to be 
taken from many places and at varying depths. (c) The methods of analysis can also be changed. In contrast to the potato sample it is also the case that (d) hypotheses, which are to be supported by samples similar to the water sample, are firstly never, in practice, exhaustible. Secondly it will always be possible that the hypotheses are replaced by better-founded hypotheses or entire theories. Thirdly it cannot be ruled out that a negative case is on hand.

Against the backdrop of points (a) to (d) we can now give a first answer as to which criteria may be used as a standard according to which the quality of water samples, respectively samples in general, may be assessed. Samples have to be projectible ${ }^{2}$, i.e. they have to have the features given in (d).

What this amounts to is that a sample is good only if further samples can be taken from the respective material (i.e. the material is not exhausted and we can therefore take further samples), if we can use the sample to support alternative hypotheses, the predicates of which are more firmly entrenched. According to Goodman we can take better entrenchment to be the following: A predicate P1 is more firmly entrenched than a predicate P2 if P1 or another predicate with the same extension has actually been projected more often than P2. Further constraints are that the predicates in question not change their extension and that all inscriptions of a predicate have the same entrenchment. An example of the second case can be seen in the following hypothesis:

$\mathrm{H}$ : Overweight persons have a disadvantage when cycling.

This hypothesis may be true today, but 1947 in post-war Germany it was false. The reason for this is, for one thing, that in 1947 persons would have been considered overweight that today would be considered normal weight, for another, that many thin persons suffered from physical exhaustion and could not have competeted with overweight persons when cycling.

A crucial point in Goodman's considerations to be observed here is that the choice of hypotheses (and accordingly theories or systems) depends not

\footnotetext{
2 At this point it becomes clear that the concept of projection in Goodman's sense precedes that of rightness (cf. Chokr 1993, 64).
} 
only on truth, but on the historicity of linguistic practice (cf. Ernst 2005, especially p.102). I.e. when we examine the entrenchment of predicates, we actually examine languages and our past linguistic practices. Not alone truth guides us, but our use of language.

[B]ut the organisation we point is effected by the use of language and is not attributed to anything inevitable or immutable in the nature of the human cognition $(F F F, 96)$.

The concept of entrenchment, one the one hand, illustrates Goodman's early interest in and appraisal of a pragmatic theory of linguistic practice and, on the other hand, provides a first criterion for, or at least a symptom of, the choice of (competing) categorial systems. It should furthermore be noted that the concept of entrenchment therefore is a gradual one.

A further expression of central importance for the following considerations, next to entrenchment, is that of projection. According to Goodman a hypothesis is "projectible when and only when it is supported, unviolated, and unexhausted, and all such hypotheses that conflicted with it are overridden" (FFF, 108). Competing hypotheses are displaced, because they are not as well supported (i.e. there are few actual cases of application) or simply false. ${ }^{3}$

As has already been suggested, projectibility plays a crucial role in the choice of hypotheses that are supported by samples. Goodman himself does not want to restrict it to hypotheses, but sees its application wherever theories, categorial systems or symbol systems are used. ${ }^{4}$ This, for example, is not done for the sole purpose of predicting events, as in the case of the hypothesis, but also for the purpose of organisation or, in the case of metaphor, the re-organisation of the most diverse of domains. How are we to understand this?

Not only in science is it common practice to demarcate domains by the use of predicates (e.g. fish, fowl, mammals). To what extent such a

\footnotetext{
${ }^{3}$ Following this definition Goodman defines the term ,,non-projectible [as follows:] when and only when it and a conflicting hypothesis are supported, unviolated, unexhausted, and not overridden; and unprobjectible when and only when it is unsupported, violated, exhausted, or overridden" $(F F F, 108)$.

${ }^{4}$ What is important is that projection is not restricted to language codified in words, but comprises all other symbol systems (cf. $L A, 201 ; W W 128,135$ ).
} 
categorisation displaces others (e.g. no longer counting whales as a kind of fish) is also a matter of projectibility. We will prefer one categorial system to another, because it is more easily projectible, i.e. because it is better supported, does not lead to contradictions, is open to new applications and has displaced competing systems.

In applying to works of art the whole breadth of the considerations made so far it is necessary to point out a further idea of Goodman's, namely that works of art mostly refer metaphorically. In what follows we will therefore give a brief sketch of his theory of metaphor and will examine whether it is also subject to his theory of projectibility.

\subsection{Metaphors in the Sciences}

Goodman's theory of metaphor is a further development of the Interaction Theory of Metaphor as put forward by I.A. Richard (1936) and M. Black (1954). The central characteristics of Goodman's theory are the following: First, metaphors cannot be less true or false than literal statements. ${ }^{5}$

Second, metaphors are pervasive throughout language and especially so in art.

Third, metaphors arise when a schema of labels (for Goodman, linguistic as well as non-linguistic symbols) for categorising a certain domain (sphere) is transferred to the categorisation of another domain.

For such a transfer to be successful three conditions must be met:

(i) A symbol $\mathbf{M}$ has to already denote or exemplify literally, ${ }^{6}$ i.e. there has to be at least one schema $\mathbf{S}$ of labels and a sphere $\mathbf{G}_{1}$, to which the categorisation, i.e. the signs are applied in a denotative sense.

(ii) There has to be a further sphere $\mathbf{G}_{2}$ and

(iii) a transfer $\mathbf{T}$ of $\mathbf{S}$ to $\mathbf{G}_{2}$.

\footnotetext{
${ }^{5}$ It has to be stressed that Goodman's constraints are contrary to all those theories of metaphor, according to which metaphors are essentially evocative and therefore truth predicates cannot be applied to them.

${ }^{6}$ How Goodman understands these two expressions can be illustrated by way of the following example: The expression "Lake Constance" denotes Lake Constance and, in turn, it exemplifies the label ,inland water". Material pictures and other symbols, too can denote or exemplify something.
} 
If we apply conditions (i-iii) to the metaphorical expression "the lake is a sapphire", we get the following structure or chain of reference: ${ }^{7}$

1. "Sapphire" denotes a sapphire.

2. A sapphire exemplifies "smooth" and "blue"

3. "Smooth" and "blue" denote the lake.

This chain of reference thus clarifies the three constraints Goodman sets for metaphors:

First, the word "sapphire" literally denotes sapphires. This is accomplished by the fact that there exists a schema $\mathbf{S}$, call it the schema for describing gems, that categorises a given sphere $\mathbf{G}_{1}$, namely gems, by the use of labels.

Second, there is a further sphere $\mathbf{G}_{2}$, the sphere of water bodies.

Third, the schema $\mathbf{S}_{1}$, the schema for describing gems ("sapphire", "smooth", "blue" etc.), is transferred to the sphere $\mathbf{G}_{2}$, the sphere of water bodies.

But to what extent are metaphors projectible? It is obvious that a new metaphor cannot be supported in the same way as a hypothesis. In the event of the first use of a metaphor there are no literally true cases of its previous application. They are unsupported and refuted in a literal sense, because they are literally false. ${ }^{8}$ Nonetheless, metaphors can be assessed as regards their projectibility. A metaphor is more useful than its alternatives if transferring it to a new sphere makes possible more correct applications and, by extension, more new insights than would have been made possible by alternative metaphors. For example, up to this day one can say that the metaphor "man is a wolf" conveys more insights than the metaphor "man is a rowing boat". For both metaphors it is the case that they have not been exhausted. However, the first metaphor is certainly better supported. Furthermore it is the case that a metaphor can be assessed according to

\footnotetext{
${ }^{7}$ The expression "Chain of reference" was coined by Goodman ( $M M$, chap. 3.1). It is important here to stress that Goodman does not hold that such chains of reference can be paraphrased, but that they serve to illuminate the structure of metaphorical reference (but also that, for instance, of allusions.).

${ }^{8}$ Possibly metaphors of the kind "This is a stony path" form an exception. Both can be true, that the path actually is stony and that it is hard to walk on, wearisome etc.
} 
how many different domains it may reasonably be transferred to. In this sense the first metaphor may certainly better be applied to the sphere of politics than to the domain of flower-lovers.

\subsection{True and other Samples}

For the following considerations it is of importance to once again point out that the concept of truth is contained within the concept of projectibility as it has been characterized so far. Only hypotheses, for which there are positive cases, are projectible. "Positive Cases" here means that there were cases or events, to which the hypothesis (a simple or complex sentence) applied, i.e. was, respectively is true. In cases of schemata not coded in the form of words the notion of truth is absent. For example, systems of musical notation or pictorial systems (e.g. cubist painting) are neither true nor false. For cases of this kind, the question arises whether there is something that takes the place of truth and therefore makes it possible to still talk of projection in these cases. For the cognitivist this question is of key importance, as she views art and science as cognitively equivalent (cf. Steinbrenner 1996, chap. I). In answering this question Goodman employs the following strategy. He replaces the central concept of truth by that of rightness. While rightness plays an important role in all symbol systems, truth is only of relevance for certain linguistic systems coded in words. No less holds true for the languages of art than for the languages of science: not truth, but rightness is their actual goal. ${ }^{9}$ For the practice of sampling this entails that only projectible samples fit and therefore are right.

Such fairness or projectibility, rather than requiring or guaranteeing agreement [being true J.St.] between the projection made and an actual feature of the whole or of further samples, depends upon conformity to good practice in interpreting samples $(W W, 135)$.

Samples of the kind of the potato sample have as their criterion agreement. A sample from the stock of potatoes for the winter is good and

\footnotetext{
${ }^{9}$ Here the starting point of Goodman's line of thought is the problem of induction, which can be seen as the paradigm of his claim that we cannot obtain a solution to the problem of induction by the concept of truth alone. (cf. $F F F$ ). Projectibility has to also be taken into consideration and it has to do primarily with rightness (cf. Steinbrenner 1996, 2.72).
} 
right if it by and large agrees, as regards taste and consistency, with the entirety of potatoes eaten throughout the winter. Such agreement can in practice never be achieved for the water sample from Lake Constance.

A key feature in which samples differ from hypotheses is that samples are mostly ${ }^{10}$ not linguistically coded in the form of words. What samples exemplify is always contingent upon a practice. As has been shown, it is the case that if samples do not support the hypotheses, for example, because they are false in most cases, the hypothesis can be replaced or the practice of sampling can be changed (cf. $W W, 136)^{11}$. The formerly good practice becomes a bad one and is replaced by another practice if it repeatedly leads to unwanted results. The quality of a sampling practice can be assessed through the projectibility of its results. Better entrenchment, in such cases, is the hallmark of a handed-down and successful sampling practice. If two samples support two conflicting hypotheses, we will reject the sample that is less well entrenched (cf. the previous Goodman quote).

Before I followingly turn to art, let me briefly address a term that I have already used repeatedly and that is of central importance for the following considerations, namely exemplification. The reason for this is, in my opinion, that samples not only support hypotheses, but also exemplify them if they are right. In this sense they are similar to works of art that, as samples, can support as well as exemplify hypotheses and interpretations. For example, a picture by Monet can exemplify "impressionist painting" and, at the same time, be used as a sample to support certain hypotheses concerning impressionism. What matters in both cases is that successful exemplification as well as right samples are subject to the criterion of projectibility. This entails that the properties, predicates or interpretations that are exemplified by a work of art are ones, which, in contrast to their alternatives, are more easily projectible. I will address this issue in more detail in what follows.

\footnotetext{
${ }^{10}$ Exceptions are linguistic and similar investigations.

11 The difference in later writings as against Goodman 1954 is that Goodman no longer is a follower of Popper. This means that a falsification ("negative cases") of a hypothesis does not necessarily lead to abandoning the hypothesis, but possibly to changing the sampling practice.
} 


\subsection{Exemplification}

First, we should note that samples, respectively exemplifying objects do not exemplify all theories, predicates etc., to which they are subject. Goodman's example here is a swatch that a tailor sends to his customer. This sample normally exemplifies colour and quality of the fabric, but not its shape. On the other hand, the paper-mâché cake in the confectioner's shop window exemplifies the shape and colour, but not the taste. To sum up, what is exemplified by a sample depends on the context, in which the sample is used. In this sense "[e]xemplification is possession plus reference" $(L A, 53)$. I.e. depending on the context certain properties that the sample has are exemplified by the sample.

Within Goodman's nominalist framework this means that the sample exemplifies certain predicates, labels, hypotheses etc. Goodman writes:

Exemplification relates the symbol to a label that denotes it, and hence indirectly to the things (including the symbol itself) in the range of the label $(L A, 92)$.

As we have seen, however, a sample cannot only literally exemplify, i.e. properties that the sample actually has, but also metaphorically. Concerning this matter, Goodman writes:

An object is literally or metaphorically denoted by a predicate, and refers to that predicate or the corresponding property, may be said to exemplify that predicate or property $(L A, 52)$.

Exemplification, according to Goodman, is the most important symptom of the aesthetic and therefore plays a pivotal role in his theory of art: The reasons for this are as follows:

First, exemplification is to explain reference-in-fiction.

Second, it is to explain how abstract art functions.

Third, Goodman's theory of expression is based on exemplification.

Fourth, it is to explain the similarities of the modes of operation in works of art and samples in the sciences.

I will give a few short examples for the first three points before I go on to address the fourth point in detail. The latter point is the one of crucial importance for my topic here. 


\section{Reference-in-fiction}

Turning to fictional signs, namely pictures or texts that are depictions or descriptions of nonexistent objects, we may ask what it means to understand such symbols. As objects such as, for example, unicorns do not exist, understanding them cannot be knowing their denotation. Goodman's solution to this challenge is that understanding, in these cases, is recognizing to which type the symbol belongs and under which descriptions it falls, respectively in which descriptions it can appear. For the picture of a unicorn this means that the picture is of the type picture of a unicorn and falls under the description "fabulous animal with a horse's body and single straight horn". The expression "unicorn", on the other hand, is of the type "description of a unicorn" and falls under the description "expression for fabulous animal with a horse's body and single straight horn". It can, for example, occur in the following descriptions: "Unicorns are fabulous animals with highly sexual connotations" or "the unicorn is creeping up on us." Understanding fictional expressions, then, is knowing which linguistic types and descriptions are exemplified by the fictional symbol. In this sense a picture of a unicorn neither exemplifies the type "picture of a mermaid" nor the description "picture of a fabulous animal that lives under water." Knowing what fictional signs mean is knowing what they exemplify. If a poet writes a new fable about a unicorn, we can see the fable as a sample, which is based on our knowledge of unicorns and the quality of which can be assessed by the degree to which it can be metaphorically projected onto certain aspects of life.

\section{Abstract painting}

Abstract paintings are similar to fictional paintings in a certain sense. They, too, do not denote. Like fictional paintings, they do not represent existing objects. Understanding abstract paintings does, however, depend on whether the observer knows how to properly categorize them i.e. whether she knows under which descriptions they fall. If, for instance, an observer believes to be seeing a depiction of a chess board in an abstract painting by Ellsworth Kelly, she is mistaken. If she recognizes that the picture exemplifies the label "checkerboard pattern", this can, however, be of advantage for a better understanding of the picture. She will, in doing 
so, for example, recognize how Kelly moved from abstraction to nonfigurative painting and how his pictures become sheer lessons in perception. That is, the observer might recognize that Kelly's pictures have features similar to perception experiments (samples!), but go beyond this comparison, as they exemplify certain aspects of the question "What is a picture?" (e.g. "Can a mere pattern be a picture?") Knowing that a picture exemplifies such questions, of course, presupposes knowledge of a sampling practice. (Namely, that of the visual arts and more specifically that of abstract painting. $)^{12}$

\section{Artistic Expression}

If we assume that phrases like "the picture expresses joy" are meaningful, we can, of course, also ask how it is possible that an inanimate object like, for example, a picture can express feelings or anything else. Usually we say only of people that they can express feelings.

Goodman's solution here is that while persons can literally express feelings, symbols can only exemplify them metaphorically. In this sense expression, for Goodman, is a special kind of metaphorical exemplification. As far as I know, Goodman does not provide a criterion how expression is to be distinguished from metaphorical exemplification. My suggestion therefore is to restrict the use of the expression "expression" to cases, in which feeling predicates are metaphorically exemplified (cf. Steinbrenner 1996, II. 1.33.2). In this sense a colourful painting, for example by Delaunay, can, at the same time, express joy and metaphorically exemplify its owner's wealth. In a nutshell: A symbol can only express feelings, respectively, expressions that express feelings, whereas it can metaphorically exemplify just about any predicate imaginable.

12 Cf. (Hölscher 2005). Christoph Baumberger pointed out to me that it is questionable whether a picture can exemplify a question. Two solutions seem possible: Either one firstly accepts that pictures can exemplify questions (not, for example, hypotheses, sentences or predicates) or secondly one tries to paraphrase the questions as ordinary declamatory sentences. A work by Robert Rymans, for example, might then exemplify the hypothesis "Alberti's thesis that pictures have properties P1 - Pn is questionable today" instead of "Is Alberti's theory of pictures still valid today?". 
Without having here addressed all subtleties concerning Goodman's understanding of exemplification (cf. Steinbrenner 2005), my hopes are high that it has transpired how important this concept is in the context of his theory of art. What needs to be further examined, however, is the fourth point, namely that artistic exemplification is parallel to the scientific practice of sampling in its crucial features.

\section{Works of Art as Samples}

If we follow Goodman in assuming that it is not the truth that is the guideline in formulating scientific hypotheses, but rightness and, by extension, projectibility, a former criterion for categorially distinguishing art and science has become obsolete (cf. Steinbrenner 1996, II.2). According to Goodman it is the common goal of scientific samples as well as works of art to provide new insights, that is, essentially to construct new categorial systems, which make us aware of useful or new connections among and similarities between different systems. As we have seen in the case of the water sample, it is precisely the goal to deduce certain features (e.g. potability) from other features. The case is similar for works of art.

An art historian, for example, is interested in finding out the common features of Rembrandt's works and from these deducing the general stylistic features of his oeuvre. To achieve this it is necessary to compare the works with one another, to form groups and, if necessary, to develop new predicates, with which it is possible to form new hypotheses concerning Rembrandt's oeuvre. In the case of Rembrandt this has recently meant that his oeuvre became smaller and several of the works so far attributed to him were attributed to his disciples. This, in turn, has resulted in his disciples being credited with more artistic significance (cf. Wiegand 2005). Aside from such stylistic issues that can concern individual artists, epochs or even more general considerations, it is, in the case of abstract art, crucial to determine what works exemplify. In order to do so it is often necessary to pay attention to features that to that point might have only been marginally acknowledged.

An example of such a feature is the frame, respectively the outer delimiting of a picture. Robert Ryman, for example in his works examined the boundary between the picture and the wall and, more specifically, the 
question of how a picture is affixed to the wall. Questions of this kind, of course, could only be asked after the picture as a medium had been fundamentally called into question. That I today can so naturally speak of such matters presupposes a "sampling practice", part of which it is that several pictures exemplify such features concerning affixation and the frame. An observer unaware of such questions will mostly be at a loss when looking at abstract paintings, since she does not know the relevant features. She might, for example, look for objects in the painting and discard Ryman's works as boring snowscapes. A sampling practice of the kind illustrated above does not only have an influence on the observation of abstract painting, but furthermore has a retrospective effect in the sense that we re-examine how painters have traditionally used frames. Ideally it follows from such a practice that we develop new stylistic features concerning the frame, which give us a deeper insight into art or even life, for that matter. We achieve this feat of cognition through works of art that may well be expressions of exactly those kinds of considerations on the part of their creators. This does not, however, always have to be the case.

In many cases features are only recognized in retrospect. Take, for example, the hairstyles in films from the 60ies. We can, for example, in retrospect detect typical colours in the hair and the film as a whole, which the contemporary stylists could hardly have been aware of, since they did not know the alternatives that are available today (cf. Steinbrenner 1998). The same holds for editing, colour quality etc., that is, features to which we would be more inclined to attribute artistic relevance.

But let us return to the example of Ryman. Not least do his works have their significance, because they allow us to "project" well founded predicates into them, that is, let them exemplify these predicates. As we have seen, this is possible, because they are predicates that denote features characteristic of Modernity. This can, for example, be seen in the fact that these features, at least subconsciously, already played an important role with the predecessors of Modernity (e.g. Manet, Degas and Monet).

Put another way, just as in the case of samples, we look to the hypotheses that we want to confirm through them, in the case of works of art, we often look for stylistic features of an epoch, an oeuvre etc. that we want to see exemplified by the work (cf. Ernst 2005, 105). For this reason it also becomes clear why we are more interested in a single work by a 
great artist than in a work similar in quality by an artist, who only achieved artistic greatness in this one work. We appreciate the work of the great artist more, because it allows us to locate it in a significant context. In Goodman's terminology we can explain it thus: The work of the great artist exemplifies more better entrenched predicates than the work of his colleague. The reason for this is that the oeuvre of the great artist, to which the work belongs, provides more possibilities for exemplification than the oeuvre of his colleague. ${ }^{13}$

So far I have mainly focussed on connections internal to art and similarities that can be exemplified by a work of art (cf. Hölscher 2005). Nonetheless it should have become clear that such a restriction is hardly necessary. Works of art can, of course, also bear witness to general human themes and their times. Just think of great novels, classical tragedies, that is, any masterpiece imaginable. It is precisely these that are our "samples" or examples of what man is, what he should do and where he wants to go. These works exemplify the leading properties (values) of a culture. At the same time, however, the way of historically dealing with these masterpieces bears witness to the way in which our sampling practice changes. Raffael's Madonna, for instance, does not essentially exemplify "naive piety" for us, but depending on context, quite a number of different things. And, of course, our canon of masterpieces is also subject to continuous revision. This runs in parallel with a change of the features that are important in our everyday lives. One need only think of the reevaluation that women writers have undergone in the wake of the feminist movement.

Goodman's significant contribution, in my opinion, lies in the fact that he has developed a theory of scientific sampling practice that we can apply to our way of dealing with art. In this sense works of art are comparable to water samples from an inexhaustible body of water. That is, works of art

13 Interestingly and not accidentally, Goodman is here close to Hume's inductive theory of art. For Hume too, those works are great that again and again are used in cultivating taste. But how do we know that these works are really great? If our answer to this question is that, in the course of history, we continually use them as evaluative standards, the spectre of circularity looms. (cf. Levinson 2002). 
can, depending on context, exemplify very different things and are, like the water sample, taken from an inexhaustible whole. ${ }^{14}$

Translated by R. Owen Hughes (Müllan)

\section{References}

Black, M. (1954): "Metaphor", in: Proceedings of the Aristotelian Society 55 (1954), 273-294.

Chokr, N. (1993): "Nelson Goodman on Truth, Relativism, and Criteria of Rightness", in: Dialectica 47 (1993), 55-73.

Danto, A. (1986): The Philosophical Disenfranchisement of Art, New York: Columbia University Press, 1986.

Ernst, G. (2005): "Induktion, Exemplifikation und Welterzeugung", in: Steinbrenner, J.; Scholz, O.R.; Ernst, G (eds): Symbole, System, Welten. Studien zur Philosophie Nelson Goodmans. Heidelberg: Synchron, 2005, 99-110.

Gombrich, E. (1977): Art and Illusion, Oxford: Phaidon, 1977.

Hölscher, T. (2005): "Goodman und die Kunstgeschichte", in: Steinbrenner, J.; Scholz, O.R.; Ernst, G (eds): Symbole, System, Welten. Studien zur Philosophie Nelson Goodmans. Heidelberg: Synchron, 2005, 89-98.

Levinson, J. (2002): "Hume's Standard of Taste: The Real Problem”, in: Journal of Aesthetics and Art Crtitcism 60 (2002). 227-238.

Richard, I. A. (1936): The Philosophy of Rhetoric. New York; London: Oxford University Press, 1936.

Steinbrenner, J. (1996): Kognitivismus in der Äshtetik. Würzburg: Königshausen \& Neumann, 1996.

Steinbrenner, J. (1998): “The Unimaginable”, in: Theory \& History: Danto and his Critics: Art History, Historiography and After the End of Art: Theme Issue 37 (1998), 115-126.

Steinbrenner, J. (2005): "Exemplifikation und Bezugnahmefeld", in: Steinbrenner, J.; Scholz, O.R.; Ernst, G (eds): Symbole, System, Welten.

${ }^{14}$ For thorough reading of and critical comments on this essay I wish to express my gratitude to Christoph Baumberger and Gerhard Ernst. 
Studien zur Philosophie Nelson Goodmans. Heidelberg: Synchron, 2005, 227-234.

Wiegand, W. (2005): "Als würde mitten im Barock ein Fenster aufgestoßen", in: Frankfurter Allgemeine Zeitung (16.05.05). 